\title{
KNOWLEDGE SHARING AMONG THE STAFF OF THE KWAME NKRUMAH UNIVERSITY OF SCIENCE AND TECHNOLOGY (KNUST) MAIN LIBRARY: A MYTH OR A REALITY?
}

\author{
E. M. Borteye, A.D. Asare-Kyire and A. K. Ofori \\ Library \\ Kwame Nkrumah University of Science and Technology, Kumasi
}

\begin{abstract}
This paper examined the level of knowledge sharing among staff of the KNUST Library. Forms in which knowledge sharing manifest itself and should manifest itself in the Library were also investigated. Questionnaires were used for the collection of data. Data collected were analysed using SPSS software. Fifty respondents were selected from both the Junior/Senior staff and Senior Members of the KNUST Main Library for the study. It was revealed from the study that knowledge sharing takes place a lot in the Library but this often comes as a by-product of ordinary conversations and discussions. Many respondents overwhelmingly stated that they share their experiences with their colleagues. More attention to be given to formal forms of knowledge sharing in the Library and the creation of culture of external knowledge sharing were some of the recommendations made to help improve on the level of knowledge sharing in the Library.
\end{abstract}

Keywords: Knowledge; knowledge sharing; knowledge management; Academic Libraries; KNUST Library

\section{INTRODUCTION}

Knowledge sharing is becoming an important issue in knowledge management (KM). There is now a shift in knowledge management from managing knowledge in organisations to rather the sharing of knowledge. Knowledge management according to Werwath (2006) "encompasses the processes, technologies and resources used by organizations to inspire, gather, manage and distribute information and knowledge".

Organizations have recognized that knowledge constitutes a valuable intangible asset for creating and sustaining competitive advantages
(Wikipedia, 2008). They thus ensure that the knowledge created and acquired in and outside the organization is shared among staff within the institution. Knowledge in a knowledge management system (KMS) can be considered to be a public good, an asset available to all members of a community or organization regardless of whether the members contributed to its constitution (Marks et al., 2008). Knowledge Management System (KM System) refers to a (generally IT based) system for managing knowledge in organizations, supporting creation, capture, storage and dissemination of information (Wikipedia, 2008). Norris et al., 
(2003) asserted that "knowledge is information presented within a particular context, yielding insight on application in that context". Norris et al., (2003) quoting Beerli et al further stated that "knowledge can be regarded as the only unique resource that grows when shared, transferred and managed skillfully".

Staples and Webster (2008) stated that "successful organizations need dynamic capabilities to create, acquire, integrate and use knowledge". Common to these capabilities is the movement of knowledge from one team member to another, typically called transfer, diffusion, distribution - or more commonly knowledge sharing (Staples and Webster, 2008).

Knowledge sharing is an activity through which knowledge (i.e. information, skills, or expertise) is exchanged among people, friends, or members of a family, a community or an organization (Wikipedia, 2008). Gwin (2003) identifies knowledge sharing "as one element in a single cycle of knowledge creation, sharing, and use". She further described the knowledge process as "the systematic capture of knowledge from research and experience; organization and storage of knowledge and information for easy access; and transfer/ dissemination of knowledge, often as a two-way exchange". In the opinion of Yoo et al., (2007) "knowledge sharing is a process of creating a mutual stock of knowledge among individuals or groups the knowledge that someone in the organization already has - through direct or indirect interaction".

Marks et al., (2008) stated that "sharing knowledge throughout an organization has intuitive appeal. If organizational members share valuable information freely with other members, the organization's responsiveness and effectiveness can be greatly augmented by preventing those members from having to repeatedly solve the same problems". They went on further to state that "in an environment of organizational sharing, a KMS can readily save time and money for both providers and users of knowledge".
The importance of knowledge sharing as mentioned therefore makes it imperative for any institution to ensure that knowledge sharing becomes part and parcel of its activities, since that is the only way it can gain competitive advantage over its competitors. The Kwame Nkrumah University of Science and Technology (KNUST) Library is not an exception to this. An organization creates the space for knowledge sharing through providing leadership and resources, and through clear articulation of roles and expectations, and then lets the emerging community run itself (Creech, 2004). This paper is based on a study which assessed the level of knowledge sharing amongst the staff at the KNUST Main Library.

\section{KNUST MAIN LIBRARY}

The University Library began in a prefabricated structure in 1952. It moved to its current location which is near the Great Hall in 1961. The KNUST Main Library is made up of six departments; namely Lending, Serials, Electronic, Reference, Acquisition and Cataloguing with a staff strength of eighty nine, comprising sixty three junior staff, fifteen senior staff and eleven senior members. The Library contains approximately 213,692 volumes and holds 584 journal titles, with a few on current subscription. The role of the University Library is to select and acquire publications to build up a comprehensive collection with regard to the goals and objectives of the University and to assist users in meeting their information needs. It also organizes, preserves and makes available relevant texts and documents that would support the teaching and research activities of the University (University Library, 2005). In addition, the Library provides photocopying, email/internet, online databases and inter-library loans services. The recently launched strategic plan of the KNUST library endorses knowledge sharing as one of the vital tools to promoting knowledge, productivity and staff development. The Plan states inter alia, that information and knowledge have become the driving force for technological and social development; the University Library, which manages information, 


\section{Borteye et al.}

therefore, aims to identify, acquire, develop, store, and share information that leads to the acquisition of knowledge; to achieve this, the University Library supports a high calibre professional as well as a well trained supporting staff to perform efficiently in a scientific environment to attain its challenging goals and objectives (University Library, 2005)

BARRIERS TO KNOWLEDGE SHARING The sharing of knowledge constitutes a major challenge in the field of knowledge management because some employees tend to resist sharing their knowledge with the rest of the organization (Wikipedia, 2008). Skyrme (2008) identified five challenges or barriers to knowledge sharing. They are "knowledge is power", the notion of "not invented here", "not realizing how useful particular knowledge is to others", "lack of trust", and "lack of time". Other barriers cited by experts include 'functional silos'this exists when the business processes of a functional unit within the division of labor of an organization focus inwardly on their functional objectives (Wikipedia, 2008), individualism, poor means of knowledge capture, inadequate technology, internal competition and topdown decision making (Skyrme, 2008).

\section{METHODOLOGY}

A number of research strategies were investigated to determine the appropriate method for the study. The case study was considered the most suitable. This is because in case studies one is able to understand the circumstances that surrounds a case and thus enables one to explain, advise, decide on, defend or reject a given situation, argument and condition (Kumekpor, 1999).

There are a number of instruments, devices or processes that are used to measure objects or human behaviour. They include questionnaire, interview and observational techniques. After a careful examination, the questionnaire was adopted as the most appropriate data collecting instrument for this study. The reasons for adopting the questionnaire are that the questionnaire helps to avoid interviewer biases. In addition the respondent is able to reflect upon questions before filling in his/her answers.

Data for this study was collected between April and May 2008 and it was administered by the authors. All of the questions were closed ended and they required a yes or no, or one response from a checklist of possible replies. The questions sought information in areas such as the gender, educational background, professional experience of respondents, forms in which knowledge is shared in the Library among others. Respondents were asked to tick, circle or underline the most appropriate option(s). In all fifty questionnaires were sent out to solicit data for this study. Out of the fifty questionnaires sent out, only forty five copies of the questionnaire representing $90 \%$ were returned for analysis. Those returned were considered to be good enough for this analysis.

The purposive sampling technique was used for the selection of the respondents. These comprised both the Junior/Senior staff and Senior Members of the KNUST Main Library. The total number of staff in the Library is eighty nine. The break-down of the questionnaires administered to the respondents is as follows: Senior Members- eleven, Senior Staff- fifteen, and Junior Staff- twenty four.

The Statistical Package for the Social Sciences (SPSS) was used for the analysis. Descriptive statistics was used to summarise the data. The data were presented in percentages using simple tables.

\section{RESULTS AND DISCUSSION \\ Gender}

Table 1 shows the gender of the respondents for the study. A large proportion $(60 \%)$ of respondents were males with only $40 \%$ consisting of

\section{Table 1: Gender}

\begin{tabular}{lcc}
\hline Gender & Frequency & Percent \\
Male & 27 & 60 \\
Female & 18 & 40 \\
Total & 45 & 100 \\
\hline
\end{tabular}


females. This though can be said to be a fair representation of the female population in the KNUST Main Library since the current female population of the Library stands at thirty two.

\section{Educational background}

Table 2 presents statistics of the educational background of the staff working in the KNUST Main Library. As illustrated in the table those

with secondary education are 27 representing $60 \%$ of the population sampled. Those with a second degree (masters) had the second largest frequency of 9 representing $20 \%$ of the population sampled. Those with diploma had $13.3 \%$, with postgraduate diploma holders obtaining $4.4 \%$. The above table indicates that the $\mathrm{Li}-$ brary has a large proportion of workers with secondary school background with only a few having masters, diploma and bachelors degree. The respondents in the secondary school bracket are made up of both junior and senior staff.

Table 2: Educational Background

\begin{tabular}{lrr}
\hline Level & Freq. & Percent \\
\hline Secondary education & 27 & 60 \\
Diploma & 6 & 13.3 \\
Bachelor & 1 & 2.2 \\
Postgraduate Diploma & 2 & 4.4 \\
Masters & 9 & 20 \\
Total & 45 & 100 \\
\hline
\end{tabular}

\section{Professional experience}

The length of time worked in the library was considered very important to this study. In pursuance of that respondents were asked to indicate the number of years that they have worked in the Library. Table 3 below therefore summarises the number of years that each of the respondents have worked in the Library. This also sums up their professional experience. From the table those who have worked in the Library between one to five years had the highest response rate representing $35.6 \%$. This was followed closely by those who have served for a period between five to ten years with $26.7 \%$. The rest of the percentages can be seen in the table. It can be seen from the table that cumulatively $82.3 \%$ of the respondents have spent at least five years working in the Library. It can also be inferred that the latter group of respondents may have acquired a lot of experiences as a result of the number years spent in the Library.

Table 3: Professional Experience

\begin{tabular}{lcc}
\hline Duration & Frequency & Percent \\
\hline Less than 1 year & 8 & 17.8 \\
1-5 years & 16 & 35.6 \\
5-10 years & 12 & 26.7 \\
More than 10 years & 9 & 20 \\
Total & 45 & 100 \\
\hline
\end{tabular}

\section{Knowledge sharing in the Library}

Table 4 below shows responses given by the respondents about knowledge sharing in the Library. Forty two respondents i.e. twenty four males and eighteen females representing 93.3\% of the population sampled responded in the affirmative. The differences between the number of males and females suggest that even though both have the zeal to share knowledge, the females feel reluctant to share freely as opposed to their male counterparts. Of these respondents, twenty four holds secondary education certificates, nine holds masters degrees, six are diploma holders, two are post graduate diploma holders and one holds a bachelors degree. Only $6.7 \%$ of the respondents said they do not share ideas or their experiences with colleagues. As can be seen in table 5, out of the number who responded in the affirmative nineteen of them representing $42.2 \%$ of the population said they often share their experiences and ideas with colleagues with seventeen representing $37.8 \%$ saying that they very often share ideas with their colleagues. Seven representing $15.6 \%$ stated that they do not very often share their experiences with colleagues. It can be inferred from the above that there is a high level of knowledge sharing in the KNUST Main Library since close to $95.6 \%$ cumula- 


\section{Borteye et al.}

tively said they have been sharing knowledge amongst themselves.

Forms of knowledge sharing in the Library Knowledge sharing often manifests itself in several forms. Respondents were therefore asked to show how knowledge sharing manifests itself in the Library. Table 6 illustrates their response for this question. A lot of options were selected by the respondents but the dominant ones were training, seminars and workshops. Training, seminars, and workshops are vital media through which knowledge is shared in the Library. Training sessions are occasionally organized for staff of the Library to upgrade their skills. Also, periodically, the Library organizes seminars for Senior Members and Senior Staff. Senior Members presents research papers on current developments in librarianship during these seminars. This recorded a frequency of twenty six which represented $57.8 \%$. This was followed by those who

Table 4: Sharing ideas with colleagues

\begin{tabular}{lcc}
\hline \multicolumn{1}{c}{ Rating } & Frequency & Percent \\
\hline Yes & 42 & 93.3 \\
No & 6.7 & 6.7 \\
Total & 45 & 100 \\
\hline
\end{tabular}

Table 5: Frequency of knowledge sharing in the Library

\begin{tabular}{lcc}
\hline Rating & Frequency & Percent \\
\hline Very Often & 17 & 37.8 \\
Often & 19 & 42.2 \\
Not very often & 7 & 15.6 \\
Never & 2 & 4.4 \\
Total & 45 & 100 \\
\hline
\end{tabular}

chose informal conversations and discussions which recorded $35.6 \%$. People very often use this medium a lot in the Library to share their experiences with their colleagues. Very often the intention is not to share knowledge but it comes as a by-product of an ordinary conversation or discussion. The least percentage of 4.4 was recorded by those who selected publications, internal correspondence and websites. Publication of articles by members of staff about current developments in librarianship often goes a long way to promote knowledge sharing in the Library. Also important in promoting knowledge sharing in the Library is internal correspondence and other information on the Library's website. These media convey very relevant information pertaining to librarianship to staff of the Library. Other effective means of facilitating knowledge sharing in the Library include staff meetings and orientation of new staff.

Table 7: Sharing knowledge with colleagues outside the library

\begin{tabular}{lcr}
\hline Rating & Frequency & Percent \\
\hline Yes & 34 & 75.6 \\
No & 10 & 22.2 \\
Missing & 1 & 2.2 \\
Total & 45 & 100 \\
\hline
\end{tabular}

\section{External knowledge sharing}

Knowledge sharing very often does not take place only within an institution. Very often people doing the same kind of job but happen to find themselves in different institutions still share ideas amongst themselves. These ideas are often aimed at sharpening the skills of staff

Table 6: Forms in which knowledge sharing manifest itself in the library

\begin{tabular}{lcc}
\hline Forms & Frequency & Percent \\
Training, seminars and workshops & 26 & 57.8 \\
Publications, internal correspondence and websites & 2 & 4.4 \\
Informal conversations and discussions & 16 & 35.6 \\
N/A & 1 & 2.2 \\
Total & 45 & 100 \\
\hline
\end{tabular}

Journal of Science and Technology ㄷN KNST April 2010 
on the job. Respondents were therefore asked to indicate whether they share their experiences with colleagues in other institutions. Table 7 above illustrates their responses to this question. Thirty four people representing $75.6 \%$ of the sampled population maintained that they share ideas with their colleagues who are outside the Library. This takes several forms. Among the forms through which knowledge is shared externally include conferences, workshops, seminars and telephone conversations with colleagues. Only ten respondents representing $22.2 \%$ said they do not share ideas with colleagues outside the Library. In Table 8, even though many responded in the affirmative that they share ideas relating to their work with colleagues, it came to light that they do not do this very often. Response for 'not very often' recorded the highest percentage of $35.6 \%$ whilst response for 'often' recorded $24.4 \%$. Those who responded 'very often' had $15.6 \%$.

Table 8: Frequency of knowledge sharing

\begin{tabular}{lcc}
\hline Rating & Frequency & Percent \\
\hline Very Often & 7 & 15.6 \\
Often & 11 & 24.4 \\
Not very often & 16 & 35.6 \\
N/A & 10 & 22.2 \\
Missing & 1 & 2.2 \\
Total & 45 & 100.0 \\
\hline
\end{tabular}

Table 9: Helpfulness of knowledge sharing in the library

\begin{tabular}{lcc}
\hline Rating & Frequency & Percent \\
Very helpful & 20 & 44.4 \\
Helpful & 17 & 37.8 \\
Fairly helpful & 6 & 13.3 \\
Not helpful & 1 & 2.2 \\
Missing & 1 & 2.2 \\
Total & 45 & 100.0 \\
\hline
\end{tabular}

\section{Helpfulness of knowledge sharing}

Table 9 illustrates the responses given by the respondents regarding the helpfulness of knowledge sharing to them. Twenty respondents representing $44.4 \%$ stated that knowledge sharing has been very helpful to them. Seven- teen respondents representing $37.8 \%$ said knowledge sharing has been helpful whilst six people stated that knowledge sharing has been fairly helpful to them. Cumulatively close to $97.8 \%$ of the respondents indicated that knowledge sharing has been helpful to them.

\section{Level of satisfaction}

Table 10 shows responses reflecting the views of respondents regarding the level of satisfaction with knowledge sharing in the Library. As can be seen from the table twenty two respondents representing $48.9 \%$ stated that they are satisfied with the level of knowledge sharing in the Library. About $28.9 \%$ was recorded for those who stated that they have been dissatisfied with the level of knowledge sharing in the Library. The subtle manifestation of the quasi clique system in the library might account for this level of dissatisfaction. Thus interaction between junior staff and the other staff groupings (senior staff and senior members) is not as smooth as it is with the senior staff/members group. Three people representing $6.7 \%$ stated that they are very satisfied with the level of knowledge sharing in the Library. Cumulatively $55.6 \%$ of the respondents showed general satisfaction with the level of knowledge sharing

Table 10: Level of satisfaction of knowledge sharing in the library

\begin{tabular}{lcc}
\hline Rating & Frequency & Percent \\
Very satisfied & 3 & 6.7 \\
Satisfied & 22 & 48.9 \\
Neutral/ not sure & 5 & 11.1 \\
Dissatisfied & 13 & 28.9 \\
Very dissatisfied & 2 & 4.4 \\
Total & 45 & 100.0 \\
\hline
\end{tabular}

Table 11: Recommendation for knowledge sharing intensification

\begin{tabular}{lcc}
\hline \multicolumn{1}{c}{ Rating } & Frequency & Percent \\
Yes & 12 & 26.7 \\
No & 2 & 4.4 \\
N/A & 28 & 62.2 \\
Missing & 3 & 6.7 \\
Total & 45 & 100.0 \\
\hline
\end{tabular}




\section{Borteye et al.}

in the Library. This number is fairly encouraging and acceptable.

\section{Intensification of knowledge sharing in the Library}

Table 11 above illustrates the responses given by the respondents for the intensification of knowledge sharing in the Library. Thirty one respondents representing $66.6 \%$ of the sampled population for this study ignored answering this question. To many of the respondents this question was not applicable to them. This can also be explained by the high level of satisfaction shown by several of them. Twelve out the sampled population of forty five representing $26.7 \%$ recommended the intensification of knowledge sharing in the Library with two respondents representing $4.4 \%$ declining to recommend. Respondents were further asked to recommend forms in which they would want knowledge sharing in the Library to take. This is illustrated by the table 12 below. As explained earlier because a lot of the respondents said they were generally satisfied with the level of knowledge sharing in the Library many of the respondents representing $75.6 \%$ declined to answer. To these respondents this question was not applicable to them. Of the number of people who answered it, ten representing $22.2 \%$ mentioned training, workshops and seminars as the preferred forms for knowledge sharing in the Library. Informal conversations and discussions had the least response of $2.2 \%$.

\section{IMPACT OF KNOWLEDGE SHARING IN KNUST MAIN LIBRARY}

There is always the interplay of services commonly rendered by each of the departments.
As evidenced in the responses to the questionnaires, library staff more often share their skills and experiences with their colleagues during training, seminars, and workshops. The latest development in charging and discharging of library materials is shared with colleagues. Beneficiaries of the shared knowledge may or may not use it depending on their areas of work within the Library. A Lending Librarian however uses the shared knowledge to improve upon the services rendered at his/her department.

For example, user education has been and continues to be the task of paraprofessionals and professionals. At present, as a result of knowledge sharing, majority of the KNUST Main Library staff could educate users on filling system, how to search through the catalogue, where to locate library materials and the appropriate conducts expected of all users. Gone are the days when users had to wait for professionals and paraprofessionals to come and orientate fresh users of the library.

Besides, everybody at any point in time is aware of what is going on in the other departments thereby ensuring the provision of uniform answers to user queries. This also ensures swift delivery of services. Through the revealed knowledge sharing media, majority of the Library staff can perform any reference related work with ease and precision.

Unfortunately, technically related issues like cataloguing and classification have not benefited much from the knowledge sharing activities in the library. The few cataloguers available would always have to be present before technically related problems can be solved.

Table 12: Recommended forms of knowledge sharing

\begin{tabular}{lcc}
\hline Rating & Frequency & Percent \\
\hline Training, workshops and seminars & 10 & 22.2 \\
N/A & 30 & 66.7 \\
Informal conversations and discussions & 1 & 2.2 \\
Missing & 4 & 8.9 \\
Total & 45 & 100 \\
\hline
\end{tabular}

Journal of Science and Technology @ KNUST April 2010 
This sometimes causes delays in the delivery of services.

\section{CONCLUSION}

Knowledge sharing is important in every organization or institution. As has been stated knowledge constitutes a valuable intangible asset for creating and sustaining competitive advantages. Skills of staff members may be sharpened and thus enhance productivity through knowledge sharing. Knowledge sharing helps to avoid repetitive application of the same solution to the same problems. Also time and money can be saved for both providers and users of knowledge in the organization that shares knowledge.

Knowledge sharing is beset with some problems despite the importance that it plays in the life of an organization. Some of the problems are: not invented here, lack of trust, knowledge is power, lack of time, technology, organizational culture just to mention a few. The Library is also faced with some of these obstacles.

In all, the study revealed that the Library has more staff with secondary school background with $82.3 \%$ of the respondents having served averagely for five years in the Library. It also identified training, seminars, and workshops as the dominant media through which knowledge is shared in the Library. Respondents also showed general appreciation for the level of knowledge sharing the Library. It is therefore heart warming to note that many respondents stated that they have been sharing ideas with colleagues within and outside the Library. Knowledge sharing in the Library is therefore not a myth but rather a reality.

\section{RECOMMENDATIONS}

It is recommended that the following formal forms of knowledge sharing: training, seminars, and workshops are given more attention since majority of the respondents mentioned them as means through which they share ideas with their colleagues.

External knowledge sharing with colleagues outside the Library in the forms of conferences, seminars, workshops, and daily telephone discussions about issues and current developments in librarianship is also highly recommended, because it often engenders good feedback and thus helps one to improve upon his/her performance.

More so an attempt should be made to get rid of the subtle quasi clique system in the Library. This is because the study revealed that $33.3 \%$ cumulatively of respondents showed general dissatisfaction about the level of knowledge sharing in the Library.

\section{REFERENCE}

Creech, H. (2004). Mobilizing IUCN's knowledge to secure a sustainable future: the IUCN knowledge management study, Winnipeg, Canada: IISD. p.13

(www.iucn.org/programme/files/3ic/KM Study_full_report.pdf) [Accessed] $14^{\overline{\mathrm{th}}}$ May, 2008

Gwin, C. (2003). Sharing knowledge: innovations and remaining challenges: an OED evaluation, Washington, D.C.: The World Bank. p.2

Kumekpor, T.K. B. (1999). Research methods and techniques of social research, Accra, Ghana: Son Life Press. p.102

Marks, P., Polak, P., McCoy, S., and Galletta, D. (2008). "How managerial prompting, group identification, and social value orientation affect knowledge-sharing behavior", Communications of the ACM. 51(2): 60-62

Norris, M. D., Mason, J., Robson, R., Lefrere, P. and Collier, G. (2003). "A revolution in knowledge sharing", EDUCAUSE Review. 38(5):17

Peter, W. (2006). Trends in knowledge management and technology based training for community, Papers of the Summit on Technology and Community Development. p.1 (www.livingcities.org/summit.pdf/ 
70 Borteye et al.

Werwath_Trends.pdf). [Accessed] $15^{\text {th }}$ May, $200 \overline{8}$

Skyrme, J. D. (2008). "The 3Cs of knowledge sharing: culture, co-opetition and commitment", I I Udate/ Entovation International News. no.64

Staples, D. S. and Webster J. (2008). "Exploring the effects of trust, task interdependence and virtualness on knowledge sharing in teams", Information Systems Journal. p.2

University Library (2005). University Library Strategic Plan (ULSP 2K14), p3-4
Yoo, Y., Lyytinen, K. and Heo, D. (2007). "Closing the gap: towards a process model of post-merger knowledge sharing", Information Systems Journal.17:322

Wikipedia (2008). Knowledge sharing (http:// en.wikipedia.org/wiki/Knowledge_Sharing) [Accessed] 10 ${ }^{\text {th }}$ May, 2008

Wikipedia (2008). Knowledge management system.http://en.wikipedia.org/wiki/Knowledge_management_system [Accessed] 20th November, 2008 